\title{
EL IMPACTO DEL DERECHO INTERNACIONAL DE LOS DERECHOS HUMANOS LABORALES EN EL ORDENAMIENTO JURÍDICO ARGENTINO
}

(SEGUNDA PARTE)

\author{
Oscar Zas* \\ Universidad Nacional de la Plata, Argentina
}

\begin{abstract}
XIII
El sistema universal cuenta con diez tratados que establecen, cada uno de ellos, un régimen por el cual sus correspondientes Comités asumen competencia para recibir y examinar "comunicaciones", vale decir, denuncias en las que se alegue que individuos que se hallen bajo la jurisdicción de un Estado Parte, son "víctimas" de una violación por este último, de las disposiciones o derechos enunciados en el instrumento respectivo. Aludimos, a: la Convención Internacional sobre la Eliminación de Todas las Formas de Discriminación Racial ( CDR art. 14); el Protocolo I del Pacto Internacional de Derechos Civiles y Políticos (PIDCP); la Convención contra la Tortura y otros tratos o penas crueles, inhumanos o degradantes (CT arts. 22 y ss.); los Protocolos Facultativos de la Convención para la Eliminación de Todas las Formas de Discriminación contra la Mujer (CEDAW) y de la Convención sobre Derechos de las Personas con Discapacidad (CD); la Convención internacional sobre la protección de los derechos de todos los trabajadores migratorios y sus familiares (CM art. 77); el Protocolo II del PIDCP (art. 5) y la Convención internacional para la protección de todas las personas contra las desapariciones forzadas ( CDF art. 31). Cabe agregar, el recientemente entrado en vigor Protocolo del Pacto Internacional de Derechos Económicos, Sociales y Culturales (PIDESC art. 2) y el Protocolo a la Convención sobre Derechos del Niño. Sólo las señaladas vías relativas a la CDR, la CT, la CDF y el Protocolo II PIDCP, son de reconocimiento facultativo para los Estados Partes: expreso, en el caso de las tres primeras, y según la modalidad opting out en el del último. La Argentina, en tal sentido, además de haber ratificado los cuatro primeros protocolos antedichos (sin formular declaración en sentido contrario respecto del Protocolo II PIDCP), reconoció las aludidas competencias, al paso que, respecto del CDR, designó al Instituto Nacional contra la Discriminación, la Xenofobia y el Racismo como órgano competente dentro del ordenamiento jurídico nacional para recibir y examinar las comunicaciones previstas en el art. 14.1 de la CDR (arts. $1^{\circ}$ y $2^{\circ}$, ley 26.162). En fecha reciente (24/10/2011) ratificó el Protocolo PIDESC ${ }^{1}$.

Es oportuno evaluar la relevancia que, para el sistema de fuentes, tienen las "decisiones" que pronuncian los Comités en ejercicio de sus competencias. Empleamos el término "decisión" por ser el más apropiado, aun cuando el Protocolo I PIDCP usa la voz "observaciones".
\end{abstract}

\footnotetext{
- Juez de la Cámara Nacional de Apelaciones del Trabajo de la Capital Federal, República Argentina. Ex Presidente de la Asociación Latinoamericana de Jueces del Trabajo. Profesor Titular Regular de Cátedra de Derecho Social de la Facultad de Ciencias Jurídicas y Sociales de la Universidad Nacional de La Plata, República Argentina.

GIaldino, Rolando, op. cit. (n. 1).
} 
Pero, más allá de la denominación, en el contencioso en juego, después del desarrollo de un trámite respetuoso del debido proceso, el Comité se verá llevado a interpretar el contenido y alcance de las normas convencionales de su competencia, para luego decidir si en el caso se ha producido o no una violación de aquéllas. En numerosos supuestos, tal cometido exigirá que el órgano realice un control de convencionalidad de las normas o prácticas nacionales. Es por ello que este régimen es el que permite a los Comités "analizar en profundidad" los preceptos convencionales. Se suma a ello, en todos los sistemas, que los Comités están compuestos por miembros o expertos de reconocida competencia en materia de derechos humanos o en la esfera del instrumento de que se trate, y de gran integridad o prestigio morales. Dichos miembros, además de propuestos y elegidos por los Estados Partes del tratado, ejercen sus funciones a "título personal", vale decir, con total independencia de todo poder externo, lo cual incluye al Estado que los propuso. Para la aludida elección, se toman en cuenta la distribución geográfica equitativa de los miembros y la representación de las diferentes formas de civilización y de los principales sistemas jurídicos.

En tales condiciones, no existe barrera alguna para integrar dichas decisiones en el ámbito de la jurisprudencia ${ }^{2}$.

Como señala caracterizada doctrina, el control de convencionalidad no se limita a la Convención Americana sobre Derechos Humanos (CADH), y a los demás instrumentos del Sistema Interamericano de Protección de Derechos Humanos (SIDH), sino que se extiende a otros convenios, como por ejemplo, los PIDESC y PIDCP ${ }^{3}$.

Si el control se limitara a la CADH, y a las resoluciones emitidas por la Corte Interamericana, se generaría una situación de regulación normativa desigualitaria que impactaría profundamente en la garantía útil de los derechos humanos consagrados expresa o implícitamente en los textos de los instrumentos internacionales, lo cual derivaría en categorías o divisiones normativas que no se condicen con su indivisibilidad e interdependencia ${ }^{4}$.

En sostén de esta postura, cabe destacar que la Corte Interamericana de Derechos Humanos ha invocado este tipo de decisiones para fundar la solución de distintos $\operatorname{casos}^{5}$.

Los Comités de Derechos Humanos de la ONU han venido dictando "observaciones generales" que, han ido conformando, con el correr del tiempo, un cuerpo jurídico vasto, y en permanente vías de expansión y revisión.

Por su intermedio, dichos órganos han ingresado en el estudio pormenorizado del contenido y alcance, tanto de las obligaciones asumidas por los Estados, cuanto de principios, derechos, garantías y libertades enunciados en los textos respectivos.

A juicio de Abramovich y Courtis, el dictado de observaciones generales son la expresión de una competencia similar a la consultiva de la Corte Interamericana de Derechos Humanos, difiriendo sólo en el aspecto procedimental, ya que son los propios Comités los que asumen la iniciativa y escogen la oportunidad y el tema a ser considerado.

$2 \quad$ Ibid.

3 SAGÜÉs, Néstor, op. cit. (n. 68).

4 Gil Domínguez, Andrés. "El control de constitucionalidad y de convencionalidad de oficio", en: Diario La Ley, 19 de diciembre de 2012, p. 4.

5 Corte Interamericana de Derechos Humanos. Opinión consultiva OC-17/2002, op.cit. (n.103), párr. 69 (invoca una decisión del Comité de Derechos Humanos para elaborar el concepto de familia), entre otras.

6 Abramovich, Víctor; Courtis, Christian. "Fuentes de interpretación de los tratados internacionales de derechos humanos por los órganos internos". En: AÑón, M. J. (Ed.). La universalidad de los derechos sociales: el reto de la inmigración. Valencia, España: Universitat de València, 2004, p. 95, nota. 12. 
Las observaciones generales han pasado a constituir una herramienta de fundamental importancia en el arsenal de promoción del Derecho Internacional de los Derechos Humanos, que deben ser seguidas no sólo por los Estados Partes del instrumento en juego, sino también por los Estados miembros de la ONU?.

Las observaciones generales, por otro lado, suelen ser un vehículo para que los Comités con competencia en materia de comunicaciones individuales, actualicen y modernicen la "jurisprudencia" asentada bajo ese régimen. También para señalar actos y omisiones que constituyen "violaciones" de los tratados y fortalecer las posibilidades de aplicación directa de las normas internacionales por los tribunales locales, sobre todo en el campo de los derechos económicos, sociales y culturales. Dictada la observación general, ésta constituirá un elemento con arreglo al cual serán examinados y, en su caso, censurados, los informes periódicos, cuando no juzgados los Estados bajo el régimen de comunicaciones ${ }^{8}$.

La Corte Interamericana de Derechos Humanos ha invocado las mentadas observaciones generales para la solución de distintos casos llegados a su conocimiento ${ }^{9}$.

La Corte Suprema de Justicia de la Nación ha señalado reiteradamente que corresponde tomar en consideración el corpus iuris elaborado por los Comités de Derechos Humanos, que actúan en las condiciones de vigencia de los tratados de derechos humanos pertinentes (conf. art. 75, inc. 22 , párr. $2^{\circ}$ de la C.N.), y, por ende, resultan intérpretes autorizados de dichos instrumentos en el plano internacional ${ }^{10}$.

\section{XIV}

Es menester recordar que en el proceso de reconocimiento universal de los derechos de los trabajadores tuvo especial gravitación la creación de la Organización Internacional del Trabajo en 1919, acontecimiento que marcó el nacimiento del derecho internacional del trabajo ${ }^{11}$.

$\mathrm{El}$ art. 37, párr. 1 de la Constitución de la OIT establece en lo pertinente: "Todas las cuestiones o dificultades relativas a la interpretación de esta Constitución y de los convenios ulteriormente concluidos por los miembros en virtud de las disposiciones de esta Constitución serán sometidos a la Corte Internacional de Justicia para su resolución [...]".

Este procedimiento fue aplicado una sola vez en lo que concierne a un convenio. Además, en 1946 fue agregado un nuevo párrafo al art. 37 de la Constitución de la OIT, que dispone que

7 Gialdino, Rolando, op. cit. (n. 1).

$8 \quad$ Ibid, pp. 361-362.

- Corte Interamericana de Derechos Humanos. Caso Acevedo Buendía y otros ("Cesantes y Jubilados de la Contraloría") vs. Perú, sentencia de $1^{\circ}$ de julio de 2009, párrs. 101 y 103 (invoca la observación general № 3 del Comité de Derechos Económicos, Sociales y Culturales en la exégesis de la progresividad regulada en el art. 26 de la Convención Americana sobre Derechos Humanos), Caso Suárez Peralta vs. Ecuador, sentencia de 21 de mayo de 2013, párr. 135 (invoca la observación general No 14 del Comité de Derechos Económicos, Sociales y Culturales para evaluar el cumplimiento del derecho a la salud), entre otras.

10 C.S.J.N., "Pérez c/Disco", op.cit. (n. 26); "Torrillo y otro c/Gulf”, op.cit. (n. 26); Fallos: 333:699, 19/05/2010, “González, Martín Nicolás c/Polimat S.A. y otro"; "Pellicori c/Colegio Público de Abogados de la Capital”, op.cit. (n. 10); Q. 64. XLVI., 24/04/2012, "Q. C., S. Y. c/Gobierno de la Ciudad de Buenos Aires" y "Asociación de Trabajadores del Estado", op.cit. (n. 26).

En los casos "Pérez", "Torrillo", "González", "Pellicori" y "Asociación de Trabajadores del Estado" se debatían cuestiones laborales y en "Q. C., S. Y." se dilucidaban cuestiones relacionadas con el alcance del derecho a la vivienda. En todos los mencionados precedentes el Supremo Tribunal Federal aplicó distintas observaciones generales del Comité de Derechos Económicos, Sociales y Culturales.

1 C.S.J.N., "Gentini y otros c/Estado Nacional", op.cit. (n. 26). 
"el Consejo de Administración podrá formular y someter a la aprobación de la Conferencia reglas para establecer un tribunal encargado de solucionar rápidamente cualquier cuestión o dificultad relacionada con la interpretación de un convenio que le fuere referida por el Consejo de Administración o en virtud de los términos de dicho convenio", mecanismo que tampoco fue adoptado.

Sin embargo, son los llamados órganos de control de la OIT de carácter cuasijudicial, los que han elaborado una extensa "jurisprudencia" en el cumplimiento de su función de supervisión de la aplicación de las normas internacionales del trabajo. Se trata sobre todo de la Comisión de Expertos en Aplicación de Convenios y Recomendaciones, y del Comité de Libertad Sindical del Consejo de Administración. Como lo expresa la Comisión de Expertos, "a efectos de desempeñar su función consistente en evaluar la aplicación de los convenios, incumbe a la Comisión examinar el significado de ciertas disposiciones de los convenios, y expresar su punto de vista al efecto" (Informe III, Parte $4^{\text {a }}, 1977$, p. 11, párrafo 32). El conocimiento de esta jurisprudencia es sumamente importante para poder apreciar los alcances de las distintas normas contenidas en un convenio.

Frente a las críticas suscitadas contra esa "jurisprudencia", en su informe de 1990, la Comisión de Expertos precisó que no le incumbía dar una interpretación definitiva de los convenios, que corresponde a la Corte Internacional de Justicia, pero que para desempeñar su función de evaluar si se da cumplimiento a las disposiciones de los convenios debía examinar el significado de ciertos de sus artículos, determinar el alcance jurídico y, si hubiese lugar, expresar su parecer al respecto. "En consecuencia, mientras la Corte Internacional de Justicia no contradiga los puntos de vista de la Comisión, éstos siguen siendo válidos y generalmente reconocidos" (Informe III, Parte 4A, 1990, p. 8, párr. 7).

Frente a las críticas fundadas en las disposiciones de la Convención de Viena sobre el Derecho de los Tratados, cabe destacar que el art. $5^{\circ}$ de este ordenamiento internacional dispone que se aplica, efectivamente, "a todo tratado que sea un instrumento constitutivo de una organización internacional y a todo tratado adoptado en el ámbito de una organización internacional". Pero luego agrega que esto es "sin perjuicio de cualquier norma pertinente de la organización internacional". Por ello, teniendo en cuenta todo el sistema especial de convenios internacionales del trabajo y sus métodos de control, el objetivo de estos convenios -consistente en proteger los derechos sociales de los trabajadores- y hasta la naturaleza de los mismos -de carácter cuasilegislativo-, el mencionado principio de interpretación establecido en la Convención de Viena puede considerarse como no aplicable a los convenios de la OIT. En efecto, si estos instrumentos tuvieran que ser interpretados a la luz de "toda práctica ulteriormente seguida" en su aplicación por las Partes, el fin mismo de los convenios, que es la promoción del progreso social, quedaría anulado por el mero hecho de que una serie de países dejaran de aplicar determinado convenio. Por el contrario, el propósito de los convenios es que la ley y la práctica de esos países cambie, para adaptarlas a los principios del convenio respectivo.

Conserva así toda su importancia la jurisprudencia de la Comisión de Expertos en Aplicación de Convenios y Recomendaciones, así como la del Comité de Libertad Sindical, que también forma parte de las instituciones tradicionales de la OIT. El valor de las opiniones expresadas por ambos órganos es tanto mayor en nuestro país, teniendo en cuenta la jerarquía que ocupan las normas de la OIT en nuestra pirámide legislativa después de la reforma constitucional de 1994, y más aún el Convenio 87 sobre la libertad sindical y la protección del derecho de sindicación, como parte del PIDESC, de nivel constitucional en virtud del art. 75, inc. 22 de nuestra Carta Magna ${ }^{12}$.

12 Von Ротовsкy, Geraldo. "Los debates en torno a la interpretación de los convenios de la OIT". En: Derecho Colectivo del Trabajo. Buenos Aires, Argentina: La Ley, 1998, pp. 205-210. 
Con respecto al valor jurídico de las interpretaciones de los organismos de control y aplicación de los Convenios de la OIT, se planteó recientemente un interesante debate entre la Comisión de Expertos en Aplicación de Convenios y Recomendaciones y los representantes de los empleadores ante la Comisión de Aplicación de Normas de la OIT.

Por considerarlo relevante, transcribimos seguidamente la parte pertinente del Informe presentado por la citada Comisión de Expertos ante el Consejo de Administración de la OIT en el año 2013:

“29. En relación con las preocupaciones expresadas por el Vicepresidente empleador en la Conferencia de junio de 2012, la Comisión tomó nota de que según dicho orador las observaciones de la Comisión son 'vistas por el mundo exterior como una forma de jurisprudencia no vinculante sobre las normas laborales'. Sin embargo, la Comisión indicó que el mundo exterior a la OIT no es el auditorio al que se dirige o que se le ha asignado, $y$ que sus opiniones y conclusiones no son vinculantes y van destinadas a los gobiernos, los interlocutores sociales y a la Comisión de la Conferencia en virtud de su bien establecida función de órgano de control de la OIT. La Comisión señaló que es consciente de que sus orientaciones se tienen en cuenta seriamente tanto en tribunales nacionales como en tribunales internacionales pero estimó que esto es un reflejo del reconocimiento de su independencia e imparcialidad como fuente, y del valor persuasivo de sus análisis y conclusiones no vinculantes. La Comisión recordó que estos análisis y conclusiones tan sólo adquieren fuerza legal en un sentido 'vinculante' si un tribunal internacional, un tribunal nacional o un instrumento nacional así lo establecen".

“30. En relación con sus métodos de trabajo, y en particular, con su examen de las memorias de los gobiernos y los comentarios de los interlocutores sociales, la Comisión recordó que se basa exclusivamente en documentos escritos y no en informaciones orales. Aunque la Comisión tomó debida nota de los comentarios bien documentados y constructivos de los interlocutores sociales, agradecería recibir mayores comentarios de los empleadores a fin de tener más información sobre sus puntos de vista. La Comisión subrayó la importancia del trabajo individual y colectivo que realiza para examinar la aplicación de los convenios, que también se beneficia de un amplio intercambio de puntos de vista entre personas procedentes de muchos contextos jurídicos, sociales y culturales. Por último, la Comisión recordó que su mandato debe entenderse necesariamente en el marco de la Constitución de la OIT que representa una base sólida para los objetivos de la Organización de eliminar la injusticia, la miseria y las privaciones que entrañan las condiciones de trabajo de un gran número de seres humanos y promover la justicia social como medio de asegurar la paz universal y duradera [...]"

“33.La Comisión quiere señalar a la atención de los mandantes los cuatro puntos siguientes:

“a) Inherente a la lógica de la aplicación. El mandato de la Comisión de Expertos establece que la Comisión tiene que examinar una serie de memorias e informaciones a fin de supervisar la aplicación de los convenios y recomendaciones. Al cumplir con sus responsabilidades, la Comisión debe señalar a la atención de la Comisión de Aplicación de Normas de la Conferencia todos los textos legislativos y todas las prácticas nacionales que no son conformes a los convenios, e indicar la gravedad de ciertas situaciones. Esto, lógica e ine- 
vitablemente requiere una evaluación, que a su vez implica cierto grado de interpretación, tanto de la legislación nacional como del texto del convenio correspondiente."

"Además, con arreglo a los métodos de trabajo que viene utilizando desde 1964 la Comisión de Expertos ha identificado más de 3000 casos de progreso (toma nota con satisfacción), lo que a su vez requiere una declaración interpretativa respecto a que los cambios que el gobierno ha introducido en la legislación y la práctica han servido para dar más efecto a un convenio ratificado, según el sentido que le ha dado la Comisión."

"b) La igualdad de trato y la uniformidad garantizan la predictibilidad de la aplicación. El enfoque de la Comisión en lo que respecta al examen del significado de los convenios da prioridad al hecho de alcanzar la igualdad de trato para todos los Estados y la uniformidad en la aplicación práctica. Este énfasis es esencial para mantener los principios de legalidad, lo que alienta a los gobiernos a aceptar los puntos de vista de la Comisión sobre la aplicación de un convenio. De este modo, la Comisión puede promover el grado necesario de seguridad jurídica para el correcto funcionamiento del sistema de la OIT"”

“c) Composición. Las opiniones de la Comisión de Expertos sobre el significado de los convenios son ampliamente aceptadas debido a que la Comisión está compuesta por personas independientes que tienen destacadas trayectorias como juristas y una experiencia directa en los diversos ordenamientos jurídicos nacionales en el marco de los cuales se debe valorar la aplicación de los convenios. La independencia de la Comisión es también una característica importante de las profesiones de sus miembros, que son generalmente jueces de tribunales nacionales o internacionales y profesores de derecho del trabajo y de derecho en materia de derechos humanos. La independencia también se puede atribuir a la forma en la que se seleccionan los miembros de la Comisión. No son designados por los gobiernos, los empleadores o los trabajadores, sino por el Consejo de Administración a recomendación del Director General. Esta combinación de independencia, experiencia y conocimientos especializados continúa siendo una considerable fuente de legitimidad adicional para los mandantes dé la OIT".

“d) Consecuencias. Los gobiernos se basan en la validez y el reconocimiento de los que gozan las observaciones, solicitudes directas y estudios generales de la Comisión de Expertos para estructurar su orientación legislativa y práctica. Si los gobiernos consideraran que las posiciones de la Comisión están de alguna manera desacreditadas o que se ha rebajado su valor, algunos de ellos se sentirían más libres para ignorar las solicitudes o invitaciones de la CEACR para que apliquen las normas. Esta situación socavaría inevitablemente el control ordenado y la aplicación predecible de las normas, que es precisamente lo que se quiso evitar al establecer y extender el mandato de la Comisión de Expertos."

"Además, la Comisión de la Conferencia, el Comité de Libertad Sindical, y el Consejo de Administración también confían en las opiniones de la Comisión de Expertos sobre el significado de las disposiciones de un determinado convenio en el curso del proceso de aplicación del mismo. Sin esta función independiente, el sistema de control perdería un componente fundamental de imparcialidad y objetividad, que es un elemento que durante 85 años ha sido esencial para el sistema de control..."

“34. Tal como señaló en la Conferencia, la Comisión considera que puede ser útil revisar ciertas ideas planteadas en el pasado y de forma recurrente en relación con su mandato." 
“a) Declaraciones de la CEACR. Durante más de 50 años, la Comisión ha expresado regularmente su opinión sobre su mandato y sus métodos de funcionamiento. Desde 2001, lo ha hecho de forma más rigurosa a través de la labor de la subcomisión sobre los métodos de trabajo. En este punto cabe plantear tres elementos que tienen una especial relevancia a este respecto:

“- En primer lugar, la Comisión ha subrayado en repetidas ocasiones su estatus como órgano imparcial, objetivo e independiente, ya que sus miembros son nombrados por el Consejo de Administración a título personal debido precisamente a su imparcialidad e independencia"

“- En segundo lugar, la Comisión ha dejado claro con regularidad que aunque su mandato no la autoriza a realizar una interpretación definitiva de los convenios (la competencia en materia de interpretación la tiene la Corte Internacional de Justicia (CIJ) en virtud del artículo 37 de la Constitución de la OIT), a fin de cumplir con su mandato de examinar y analizar la aplicación de los convenios debe formular y expresar sus opiniones sobre el alcance jurídico y el significado de las disposiciones de dichos convenios"

“- En tercer lugar, por lo menos desde los años 1950, la Comisión ha expresado sus opiniones sobre el significado de determinados instrumentos de la OIT utilizando unos términos y un vocabulario que inevitablemente son los de la interpretación."

“b) Declaraciones del Grupo de los Empleadores. Durante los últimos 25 años, el Grupo de los Empleadores con frecuencia ha dejado claro su apoyo y aceptación de la función de la Comisión de interpretar los textos de los convenios, como un elemento fundamental del sistema de control."

"De esta forma, por ejemplo, en 1986 en la Comisión de Aplicación de Normas de la Conferencia, «los miembros empleadores declararon que a su juicio las críticas formuladas sobre el procedimiento de control probaban la eficacia de éste. Rechazaban toda idea consistente en abolir o debilitar el sistema de control. En su opinión, los argumentos esgrimidos contra este sistema carecían de fundamento. Tal era el caso, en particular, de las críticas según las cuales el sistema de control constituía una injerencia en los asuntos internos de un Estado. Al contrario, se trataba de saber si un Estado Miembro se proponía cumplir los compromisos por él suscritos. El sistema de control presentaba la ventaja de trabajar a partir de memorias recibidas directamente de los Estados Miembros y sobre la base del diálogo que se instauraba con el Estado correspondiente una vez recibidas las memorias. Este procedimiento era claro, equitativo, desprovisto de toda ambigüedad, y ante todo, necesario" (párrafo 36, pág. 31/8)"

"De nuevo en 1987, los empleadores respondieron a los argumentos de la URRS y otros países de Europa del Este (párrafo 26) de que la Comisión de Expertos había ido más allá de su mandato, que era puramente técnico, convirtiéndose en 'una especie de tribunal supranacional que interpretaba las leyes nacionales y los convenios' aunque dicha interpretación era responsabilidad de los tribunales nacionales o de la CIJ. El portavoz de los empleadores 'rechazó el argumento de que la Comisión de Expertos había excedido su mandato' (párrafo 27) y tanto el portavoz de los empleadores como el portavoz de los trabajadores 'se pronunciaron por el mantenimiento de los presentes métodos de trabajo de la Comisión de Expertos' (párrafo 32)" 
“En 1990, los empleadores criticaron un párrafo de un informe de la Comisión porque opinaban que quería decir que a falta de una sumisión a la CIJ, la competencia en materia de interpretación recaería sólo en la Comisión de la Conferencia (párrafo 22). Tras un amplio debate tripartito, los empleadores hicieron hincapié en que para ellos la Convención de Viena constituía 'el instrumento apropiado - y, por otra parte, el único - para interpretar los convenios de la OIT. Invitaban a la Comisión de Expertos a utilizar este instrumento cuando interpretaran las normas internacionales del trabajo» (párrafo 30, cursivas agregadas)"

"En 1993, los empleadores señalaron que "los desacuerdos entre el método y la sustancia de interpretaciones solamente existen en relación con un reducido número de los numerosos comentarios formulados durante estos años por la Comisión de Expertos» (párrafo 21)"

“En 2010, los empleadores hicieron hincapié en 'que no ponen en tela juicio la valiosa función que cumple la Comisión de Expertos, sino simplemente algunas de sus interpretaciones' (párrafo 75) [...]"

"35.a) Al afirmar que sus opiniones deben considerarse como válidas y generalmente reconocidas (a falta de una sentencia en sentido contrario de la CIJ), la Comisión no está diciendo que considere que sus opiniones tengan valor de cosa juzgada (res judicata) o ningún efecto equiparable. La Comisión no se considera a sí misma como un tribunal. De hecho, ha dejado claro en todo momento que sus directrices - que adoptan la forma de opiniones o recomendaciones en el marco de observaciones, solicitudes directas y estudios generales - no son vinculantes. Por el contrario, el valor persuasivo que tienen las directrices de la Comisión para los Estados Miembros, los interlocutores sociales, la Comisión de Aplicación de Normas y otros destinatarios dentro de la OIT radica en: 1) su relación lógica con el proceso de aplicación de normas; 2) la igualdad de trato y uniformidad que acompaña su aplicación; 3) la calidad de sus razonamientos, y 4) el reconocimiento general de la independencia y conocimientos especializados de la Comisión en su conjunto."

"b) En este sentido, la orientación de la Comisión forma parte del denominado panorama jurídico internacional. Al igual que la labor de los organismos independientes de supervisión creados en los organismos del sistema de las Naciones Unidas que se ocupan de los derechos humanos y de los derechos del trabajo 12, las opiniones o conclusiones no vinculantes de la Comisión gracias a su racionalidad y valor persuasivo, su fuente de legitimación (entendiendo por tal la independencia, el prestigio, la experiencia y los conocimientos especializados de sus integrantes) y su capacidad de aportar respuestas a una serie de realidades nacionales, incluyendo las informaciones que le llegan de los interlocutores sociales, pretenden orientar las medidas que adoptan los Estados Miembros de la OIT. Al mismo tiempo, la Comisión observa que los interlocutores sociales sólo pueden plantear sus preocupaciones en relación con la aplicación de los convenios ante los mecanismos de control de la OIT [...]".

“5 CIT, Informe III (Parte IV), 1957, párrafo 15; CIT, Informe III (Parte IV), 1967, párrafo 25; CIT, Informe III (Parte 4A), 1977, párrafo 12; CIT, Informe III (Parte 4A), 1987, párrafo 19; CIT, Informe III (Parte 4A), 1990, párrafo 6; CIT, Informe III (Parte 4A), 1991, párrafo 12; CIT, Informe III (Parte IA), 2006; CIT, Informe III (Parte IA), 2011, párrafo 10." 
“6 CIT, CEACR, Informe III (Parte 4A), 1977, párrafo 32; CIT, CEACR, Informe III (Parte 4A), 1987, párrafo 21; CIT, CEACR, Informe III (Parte 4A), 1990, párrafo 7; CIT, Informe III (Parte 4A), 1991, párrafo 9; CIT, CEACR, Informe III (Parte 1A), 2011, párrafo 11."

"7 CIT, Actas Provisionales núm. 31: Informe de la Comisión de Aplicación de Normas, 72. ${ }^{a}$ reunión, Ginebra, 1986, pág. 31/1.

$8 \mathrm{CIT}$, Actas Provisionales núm. 24 (Parte 1): Informe de la Comisión de Aplicación de Normas, 73. a reunión, Ginebra, 1987, pág. 24/8."

“9 CIT, Actas Provisionales núm. 27 (Parte 1): Informe de la Comisión de Aplicación de Normas, 77. a reunión, Ginebra, 1990,pág. 27/9."

"10 CIT, Actas Provisionales núm. 25 (Parte 1): Informe de la Comisión de Aplicación de Normas, 80. reunión, Ginebra, 1993, pág. 25/5."

"11 CIT, Actas Provisionales núm. 16 (Parte 1): Informe de la Comisión de Aplicación de Convenios y Recomendaciones, 99.a reunión, Ginebra, 2010, 16 Parte I/25.”

"12 El Comité de Derechos Económicos, Sociales y Culturales y el Comité de Derechos Humanos tienen responsabilidades comparables en lo que respecta al seguimiento de la aplicación de las disposiciones de sus pactos, en base a su imparcialidad y su condición de órganos expertos independientes."

Las interpretaciones de los organismos de control y aplicación de los Convenios de la OIT han sido tenidas en cuenta por la Corte Interamericana de Derechos Humanos para la solución de casos llegados a su conocimiento ${ }^{13}$.

Por otra parte, el art. 24 , párr. $3^{\circ}$, inc. b) de la ley 25.877 reenvía a los criterios de los organismos de control de la OIT para la calificación excepcional como servicio esencial de un servicio público de importancia trascendental en caso de huelga, y el último párrafo de la norma citada prescribe que su reglamentación deberá ser efectuada conforme los principios de la OIT.

Por último, la Corte Suprema de Justicia de la Nación ha invocado reiteradamente la doctrina de los mencionados organismos de control para fundar sus decisiones ${ }^{14}$.

13 Corte Interamericana de Derechos Humanos. Caso Baena Ricardo y otros vs. Panamá, sentencia de 2 de febrero de 2001, párrs. 162, 163, 164 y 171 (invoca las interpretaciones de la Comisión de Expertos y del Comité de Libertad Sindical de la OIT para dilucidar el contenido y alcance de la libertad sindical) y Caso Huilca Tecse vs. Perú, sentencia de 2 de febrero de 2001, párr. 75 (invoca las interpretaciones del Comité de Libertad Sindical de la OIT para dilucidar el contenido y el alcance de la libertad sindical). Cabe destacar especialmente que en el Caso Baena, el cimero tribunal americano considera que la libertad sindical reviste la mayor importancia para la defensa de los intereses legítimos de los trabajadores y se enmarca en el corpus juris de los derechos humanos, cita textualmente el tramo del Preámbulo de la Constitución de la OIT que consagra el "reconocimiento del principio de libertad sindical" como requisito indispensable para "la paz y armonía universales", e invoca los Convenios 87 y 98 de la OIT (párr. 157 y 158 y nota 59).

14 C.S.J.N., "Aerolíneas Argentinas c/Ministerio de Trabajo", op.cit. (n. 10) (invoca la doctrina la Comisión de Expertos para dilucidar el contenido y el alcance de las normas internacionales referidas a la inspección del trabajo); "Pérez c/Disco", op.cit. (n.26) (invoca la doctrina del Comité de Expertos para definir el concepto y alcance de la remuneración regulada por el Convenio 95 de la OIT y su compatibilidad con las normas legales argentinas cuestionadas); "Asociación Trabajadores del Estado c/Ministerio de Trabajo", op.cit. (n.15) (invoca la doctrina de la Comisión de Expertos y del Comité de Libertad Sindical para definir el concepto y alcance de la libertad sindical regulada por el Convenio 87 de la OIT y su compatibilidad con una norma de la ley argentina de asociaciones sindicales No 23.551); Fallos: 332:2715, 09/12/2009, "Rossi, Adriana María c/Estado Nacional Armada Argentina" (invoca la doctrina de la Comisión de Expertos y del Comité de Libertad Sindical para definir el concepto y alcance de la libertad sindical regulada por el Convenio 87 de la OIT y su compatibilidad con otra norma de la ley argentina de asociaciones sindicales No 23.551) y "Asociación de Trabajadores del Estado", op.cit. (n. 26) (invoca la doctrina de la Comisión 
Consideramos relevante transcribir un tramo de la sentencia dictada por el Supremo Tribunal Federal de la Argentina en el caso "Asociación de Trabajadores del Estado c/Ministerio de Trabajo":

“[...] Que este orden conceptual se corresponde con la interpretación del Convenio No 87 y la labor de los órganos de control internacional de la OIT. Por un lado, el Comité de Libertad Sindical -creado por el Consejo de Administración de la OIT en su 117ª reunión de noviembre de 1951-, destinado al examen de las alegaciones relativas a la violación de la libertad sindical (Compendio normativo aplicable al Consejo de Administración de la Oficina Internacional del Trabajo, adoptado por el Consejo en su 292a reunión, marzo de 2005, anexos I y II). Por el otro, la Comisión de Expertos en Aplicación de Convenios y Recomendaciones de la OIT -instituido por resolución adoptada por la Conferencia Internacional del Trabajo en su octava reunión (1926)- que ejerce el control regular de la observancia por los Estados Miembros de las obligaciones derivadas de los convenios que han ratificado (Manual sobre procedimientos en materia de convenios y recomendaciones internacionales del trabajo, Sección VI). De estas fuentes, por lo demás, hizo mérito la Corte Interamericana de Derechos Humanos tanto en Huilca Tecse (cit., párr. 75) cuanto en Baena (cit., párrs. 157, 164 y 165). Y tampoco ha faltado la oportunidad para que el Comité de Derechos Económicos, Sociales y Culturales exhortara a un Estado a que revise su legislación laboral con vistas a adaptarla a las observaciones de la Comisión de Expertos relativas al Convenio No 87 (vgr.: Concluding Observations: Malta, 27-11-2004, E/C.12/1/ Add. 101, párr. 35 y Concluding Observations: Poland, 29-11-2002, E/C/C.12./1.Add. 82, párr. 44) [...]".

Por las razones expuestas precedentemente, consideramos que en el ordenamiento jurídico argentino, la doctrina de la Comisión de Expertos en Aplicación de Convenios y Recomendaciones y del Comité de Libertad Sindical constituye fuente de interpretación de los Convenios de la OIT, salvo que fuera dejada sin efecto por la Corte Internacional de Justicia en los casos en que se acudiera al mecanismo previsto en el art. 37 de la Constitución de esa organización internacional.

En ese marco, los jueces y tribunales nacionales deberán tener en cuenta esa doctrina a fin de realizar el control de convencionalidad en los casos pertinentes sometidos a su consideración, sin perjuicio -claro está- de aplicar otra norma más favorable al trabajador que la contenida en el Convenio de la OIT involucrado, o de escoger una interpretación más favorable a aquel sujeto de preferente tutela que la sustentada por los organismos de control de la OIT.

Cabe recordar al respecto que el art. 19, párrafo 8 de la Constitución de la OIT dispone claramente:

“[...] En ningún caso podrá considerarse que la adopción de un convenio o de una recomendación por la Conferencia, o la ratificación de un convenio por cualquier Miembro, menoscabará cualquier ley, sentencia, costumbre o acuerdo que garantice a los trabajadores condiciones más favorables que las que figuren en el convenio o en la recomendación" ${ }^{15}$.

de Expertos para definir el concepto y alcance de la libertad sindical regulada por el Convenio 87 de la OIT y su compatibilidad con otra norma de la ley argentina de asociaciones sindicales No 23.551).

15 Considero relevante destacar que en un caso planteado ante el tribunal del trabajo que integro, donde un sindicato de policías reclamaba el derecho a obtener su inscripción sindical, me aparté del criterio adoptado por el Comité de Libertad Sindical que había desestimado esa petición y, por aplicación de la directiva establecida en el art. 19.8 de la OrT, propuse admitir 


\section{$\mathrm{XV}$}

Hoy en día, el Derecho de los derechos humanos, punto de convergencia del Derecho Internacional y del Derecho constitucional, admite la existencia de normas supranacionales que se imponen a la soberanía de los Estados en aquellas materias que son de orden público internacional, por constituir principios básicos de la convivencia internacional. Estos, que constituyen el denominado "jus cogens", incluyen el respeto de los derechos fundamentales por encima de intereses y voluntad de los Estados.

Esta ampliación de contenidos, sujetos y fronteras, se corresponde perfectamente con la globalización, produciéndose una racionalización de la soberanía nacional al incorporar normas supraestatales inherentes al ser humano y -sobre todo-, constatando la universalidad de los derechos humanos, en vez de su mera internacionalidad o constitucionalidad.

La noción de jus cogens está consagrada en el art. 53 de la Convención de Viena sobre Derechos de los Tratados, en tanto "norma aceptada y reconocida por la comunidad internacional de Estados en su conjunto como norma que no admite acuerdo en contrario y que sólo puede ser modificada por una norma ulterior de Derecho internacional general que tenga el mismo carácter".

Las normas del jus cogens obligan a todos los Estados y a los nacionales de dichos países, tienen carácter erga omnes y pueden ser reclamadas por cualquier persona o Estado, aún al margen de cualquier vínculo convencional o ratificación ${ }^{16}$.

La Corte Interamericana de Derechos Humanos sostiene que el principio de igualdad y no discriminación, inclusive en materia laboral, ha ingresado en el dominio del jus cogens, en virtud de los argumentos que, en lo sustancial, expondremos seguidamente.

La no discriminación, junto con la igualdad ante la ley y la igual protección de la ley a favor de todas las personas, son elementos constitutivos de un principio básico y general relacionado con la protección de los derechos humanos. El término discriminación hace referencia a toda exclusión, restricción o privilegio que no sea objetivo y razonable, que redunde en detrimento de los derechos humanos.

Existe un vínculo indisoluble entre la obligación de respetar y garantizar los derechos humanos y el principio de igualdad y no discriminación. Los Estados están obligados a respetar y garantizar el pleno y libre ejercicio de los derechos y libertades sin discriminación alguna. El incumplimiento por el Estado, mediante cualquier tratamiento discriminatorio, de la obligación general de respetar y garantizar los derechos humanos, le genera responsabilidad internacional.

El hecho de estar regulado el principio de igualdad y no discriminación en tantos instrumentos internacionales, es un reflejo de que existe un deber universal de respetar y garantizar los derechos humanos, emanado de aquel principio general y básico.

El principio de igualdad y no discriminación posee carácter fundamental para la salvaguardia de los derechos humanos tanto en el derecho internacional como en el interno. Por consiguiente, los Estados tienen la obligación de no introducir en su ordenamiento jurídico regulaciones

la pretensión del reclamante con fundamento en los arts. 14 bis y 19 de la Constitución Nacional y en normas internacionales de derechos humanos de jerarquía constitucional y supralegal (Cámara Nacional de Apelaciones del Trabajo, Sala V, sentencia definitiva No 72.667, 22/10/2010, "Sindicato Policial Buenos Aires c/Ministerio de Trabajo", voto del juez Zas).

16 ERMIDA, Oscar. "La declaración Sociolaboral del Mercosur y su eficacia jurídica”. En: Eficacia jurídica de la Declaración Sociolaboral del Mercosur. Trabajos de la Reunión Técnica celebrada en Buenos Aires los días 10 y 11 de diciembre de 2001, Asociación Argentina de Derechos del Trabajo y de la Seguridad Social, Oficina Internacional del Trabajo, Buenos Aires: Argentina, 2002, pp. 19-20. 
discriminatorias, de eliminar de dicho ordenamiento las regulaciones de carácter discriminatorio y de combatir las prácticas discriminatorias.

El Comité de Derechos Humanos de las Naciones Unidas definió a la discriminación como toda distinción, exclusión, restricción o preferencia que se basen en determinados motivos, como la raza, el color, el sexo, el idioma, la religión, la opinión política o de otra índole, el origen nacional o social, la posición económica, el nacimiento o cualquier otra condición social, y que tengan por objeto o resultado anular o menoscabar el reconocimiento, goce o ejercicio, en condiciones de igualdad, de los derechos humanos y libertades fundamentales de todas las personas ${ }^{17}$.

El concepto de jus cogens ha estado en sus orígenes ligado particularmente al derecho de los tratados. Tal como está formulado el jus cogens en el artículo 53 de la Convención de Viena sobre el Derecho de los Tratados, "es nulo todo tratado que, en el momento de su celebración, esté en oposición con una norma imperativa de derecho internacional general". Por su parte, el artículo 64 de la misma Convención se refiere al jus cogens superviviente, al señalar que "si surge una nueva norma imperativa de derecho internacional general, todo tratado existente que esté en oposición con esa norma se convertirá en nulo y terminará”. El jus cogens ha sido desarrollado por la doctrina y la jurisprudencia internacionales.

En su evolución y por su propia definición, el jus cogens no se ha limitado al derecho de los tratados. El dominio del jus cogens se ha ampliado, alcanzando también el derecho internacional general, y abarcando todos los actos jurídicos. El jus cogens se ha manifestado, así, también en el derecho de la responsabilidad internacional de los Estados, y ha incidido, en última instancia, en los propios fundamentos del orden jurídico internacional.

El principio de igualdad ante la ley, igual protección de la ley y no discriminación, pertenece al jus cogens, puesto que sobre él descansa todo el andamiaje jurídico del orden público nacional e internacional y es un principio fundamental que permea todo ordenamiento jurídico. Hoy día no se admite ningún acto jurídico que entre en conflicto con dicho principio fundamental, no se admiten tratos discriminatorios en perjuicio de ninguna persona, por motivos de género, raza, color, idioma, religión o convicción, opinión política o de otra índole, origen nacional, étnico o social, nacionalidad, edad, situación económica,_patrimonio, estado civil, nacimiento o cualquier otra condición. Este principio (igualdad o no discriminación) forma parte del derecho internacional general. En la actual etapa de la evolución del derecho internacional, el principio fundamental de igualdad y no discriminación ha ingresado en el dominio del ius cogens ${ }^{18}$.

En el mismo sentido, la caracterizada doctrina, con apoyo en jurisprudencia de la Corte Internacional de Justicia y de la Corte Interamericana de Derechos Humanos, afirma que la prohibición de la discriminación en sus diferentes modalidades se encuentra recogida en una norma imperativa del Derecho Internacional General.

Así, la prohibición de la discriminación en el ámbito laboral constituye en la etapa actual del Derecho Internacional un derecho humano laboral recogido en normas imperativas o de ius cogens. En otras palabras, es una prohibición que constituye el ius cogens laboral ${ }^{19}$.

Como señalamos precedentemente (ver capítulo $\mathrm{V}$ ) el derecho de acceso a la jurisdicción integra el jus cogens, máxime si el reclamo incoado es de naturaleza laboral.

\footnotetext{
17 ONU. Comité de Derechos Humanos, Observación General 18, No discriminación, 10/11/89, CCPR/C/37, párr. 7.

18 Corte Interamericana de Derechos Humanos. Opinión consultiva, op.cit. (n. 94).

19 CANESSA, Miguel F. "Los derechos humanos laborales, el núcleo duro de derechos (core rights) y el jus cogens laboral", en: Revista del Ministerio de Trabajo y Asuntos Sociales, $n^{\circ} 72$, p. 144. España.
} 
Según Gialdino, el núcleo duro de todos y cada uno de los derechos económicos, sociales y culturales, que conlleva a las obligaciones mínimas, apareja necesariamente que, al menos en esta medida, queden comprendidos en el ámbito del jus $\operatorname{cogens}^{20}$.

\section{XVI}

El principio de progresividad relativo a la obligación del Estado de lograr la plena efectividad de los derechos económicos, sociales y culturales y la prohibición de regresividad o de retroceso social también forma parte del bagaje teórico del Derecho Internacional de los Derechos Humanos.

Las fuentes normativas más importantes son el art. 2.1 del PIDESC, el art. 26 de la CADH y el art. 1 del Protocolo de San Salvador (PSS).

El art. 2.1 del PIDESC establece:

"Cada uno de los Estados Partes en el presente Pacto se compromete a adoptar medidas, tanto por separado como mediante la asistencia y la cooperación internacionales, especialmente económicas, hasta el máximo de los recursos de que disponga, para lograr progresivamente, por todos los medios apropiados, inclusive en particular la adopción de medidas legislativas, la plena efectividad de los derechos aquí reconocidos".

$\mathrm{El}$ art. 26 de la $\mathrm{CADH}$ prescribe:

"Los Estados Partes se comprometen a adoptar providencias, tanto a nivel interno como mediante la cooperación internacional, especialmente económica y técnica, para lograr progresivamente la plena efectividad de los derechos que se derivan de las normas económicas, sociales y sobre educación, ciencia y cultura, contenidas en la Carta de la Organización de los Estados Americanos, reformada por el Protocolo de Buenos Aires, en la medida de los recursos disponibles, por vía legislativa u otros medios apropiados".

El art. 1 del PSS dispone:

"Los Estados Partes en el presente Protocolo Adicional a la Convención Americana sobre Derechos Humanos se comprometen a adoptar las medidas necesarias tanto de orden interno como mediante la cooperación entre los Estados, especialmente económica y técnica, hasta el máximo de los recursos disponibles y tomando en cuenta su grado de desarrollo, a fin de lograr progresivamente, y de conformidad con la legislación interna, la plena efectividad de los derechos que se reconocen en el presente Protocolo".

La obligación de no regresividad constituye una limitación que los tratados de derechos humanos pertinentes y la Constitución Nacional imponen sobre los Poderes Legislativo y Ejecutivo a las posibilidades de reglamentación de los derechos sociales. Desde la perspectiva del titular del derecho, la obligación constituye una garantía de mantenimiento de los derechos sociales de los que goza desde la adopción de la norma que los consagre, y de su nivel de goce, a partir de dicha adopción y de toda mejora que hayan experimentado desde entonces. Se trata de una garantía de

20 Gialdino, Rolando, op. cit. (n. 1). 
carácter sustantivo, es decir, de una garantía que tiende a proteger el contenido de los derechos vigentes al momento de adopción de la obligación internacional, y el nivel de goce alcanzado cada vez que el Estado, en cumplimiento de su obligación de progresividad, haya producido una mejora $^{21}$.

El PIDESC establece, como regla, la prohibición de retroceso, vale decir, de disminución del grado de protección que hubiesen alcanzado, en un determinado momento, los derechos económicos, sociales y culturales, máxime cuando la orientación de aquél no es otra que la "mejora continua de las condiciones de existencia", según dispone su art. 11.1. Por otra parte, el art. 5.2 del PIDESC no justificaría un retroceso de la ley nacional por el hecho de que el tratado no previera el derecho en juego o lo enunciara en menor grado.

Según el Comité de Derechos Económicos, Sociales y Culturales (CDESC) el objetivo general y la razón de ser del PIDESC es establecer claras obligaciones para los Estados Partes con respecto a la plena efectividad de los derechos de que se trata. Este impone así una obligación de proceder lo más expedita y eficazmente posible con miras a lograr ese objetivo. Además, todas las medidas de carácter deliberadamente retroactivo en ese aspecto requerirán la consideración más cuidadosa y deberán justificarse plenamente por referencia a la totalidad de los derechos previstos en el Pacto y en el contexto del aprovechamiento pleno del máximo de los recursos de que se disponga ${ }^{22}$.

En la Observación General No 14 referida al derecho a la salud el CDESC precisó más su doctrina en los siguientes términos:

"Al igual que en el caso de los demás derechos enunciados en el Pacto, existe una fuerte presunción de que no son permisibles las medidas regresivas adoptadas en relación con el derecho a la salud. Si se adoptan cualesquiera medidas deliberadamente regresivas, corresponde al Estado Parte demostrar que se han aplicado tras el examen más exhaustivo de todas las alternativas posibles y que esas medidas están debidamente justificadas por referencia a la totalidad de los derechos enunciados en el Pacto en relación con la plena utilización de los recursos máximos disponibles del Estado Parte"23.

La Observación General No 18 del CDESC relativa al derecho al trabajo ha reiterado este criterio hermenéutico: "As for all other rights in the Covenant, there is a strong presumption that retrogressive measures taken in relation to the right to work are not permissible"24.

La Observación General No 19 del CDESC relativa al derecho a la seguridad social profundiza el mencionado criterio en los siguientes términos:

\footnotetext{
21 Courtis, Christian. "La prohibición de regresividad en materia de derechos sociales: apuntes introductorios". En: CourTis, Christian (Comp.) Ni un paso atrás. La prohibición de regresividad en materia de derechos sociales. Buenos Aires, Argentina: Centro de Asesoría Laboral, Centro de Estudios Legales y Sociales, Editores del Puerto, 2006, pp. 17-18.

22 Comité de Derechos Económicos, Sociales y Culturales, observación general № 3, "La índole de las obligaciones de los Estados Partes (párr. 1 del art. 2 del Pacto), 14/12/1990.

23 Comité de Derechos Económicos, Sociales y Culturales, Observación General No 14, "El derecho al disfrute del más alto nivel posible de salud (artículo 12 del Pacto Internacional de Derechos Económicos, Sociales y Culturales), 11/08/2000.

24 Comité de Derechos Económicos, Sociales y Culturales, Observación General No 18, "El derecho al trabajo", aprobada el 24/11/2005. Como señala acertadamente Gialdino, Rolando, op.cit. (n. 1), corresponde citar la versión inglesa, pues es la original y permite advertir que la traducción al castellano que proporciona la ONU es incorrecta: "En cuanto a los demás derechos del Pacto, existe la intuición generalizada de que las medidas regresivas adoptas en relación con el derecho al trabajo no son permisibles".
} 
"Existe una fuerte presunción de que la adopción de medidas regresivas con respecto a la seguridad social está prohibida de conformidad con el Pacto. Si se adoptan medidas deliberadamente regresivas, corresponde al Estado Parte la carga de la prueba de que estas medidas se han adoptado tras un examen minucioso de todas las alternativas posibles y que están debidamente justificadas habida cuenta de todos los derechos previstos en el Pacto, en el contexto del pleno aprovechamiento del máximo de los recursos de que dispone el Estado Parte. El Comité examinará detenidamente: a)si hubo una justificación razonable de las medidas; b)si se estudiaron exhaustivamente las posibles alternativas; $c$ )si hubo una verdadera participación de los grupos afectados en el examen de las medidas y alternativas propuestas; d)si las medidas eran directa o indirectamente discriminatorias; e)si las medidas tendrán una repercusión sostenida en el ejercicio del derecho a la seguridad social o un efecto injustificado en los derechos adquiridos en materia de seguridad social, o si se priva a alguna persona o grupo del acceso al nivel mínimo indispensable de seguridad social; y f) si se hizo un examen independiente de las medidas a nivel nacional".

En febrero de 2003, la Corte Interamericana de Derechos Humanos tuvo la oportunidad de resolver un caso vinculado a la vulneración de la prohibición de regresividad en materia de pensiones.

En ese caso, la Comisión Interamericana de Derechos Humanos y los representantes de las presuntas víctimas y sus familiares alegaron el incumplimiento del art. 26 de la CADH, en cuanto el Estado peruano, al haber reducido el monto de las pensiones de las presuntas víctimas, no habría cumplido el deber de dar el desarrollo progresivo de sus derechos económicos, sociales y culturales, particularmente no les habría garantizado el desarrollo progresivo al derecho a la pensión.

El tribunal cimero americano, luego de afirmar que los derechos económicos, sociales y culturales tienen una dimensión tanto individual como colectiva, señaló con un criterio muy discutible que su desarrollo progresivo:

“...se debe medir...en función de la creciente cobertura de los derechos económicos, sociales y culturales en general, y del derecho a la seguridad social y a la pensión en particular, sobre el conjunto de la población, teniendo presentes los imperativos de la equidad social, y no en función de las circunstancias de un muy limitado grupo de pensionistas no necesariamente representativos de la situación general prevaleciente [... $]^{\text {25 }}$.

Sin embargo, con posterioridad la Corte Interamericana modificó el aludido criterio, en los siguientes términos:

“[...] El Tribunal observa que el desarrollo progresivo de los derechos económicos, sociales y culturales ha sido materia de pronunciamiento por parte del Comité de Derechos Económicos, Sociales y Culturales de las Naciones Unidas, en el sentido de que la plena efectividad de aquéllos "no podrá lograrse en un breve período de tiempo" y que, en esa medida "requiere un dispositivo de flexibilidad necesaria que refleje las realidades del mundo [...] y las dificultades que implica para cada país el asegurar [dicha] efectividad. En el marco de

25 Corte Interamericana de Derechos Humanos, Caso "Cinco Pensionistas" vs. Perú, sentencia de 28 de febrero de 2003 , párr. 147. 
dicha flexibilidad en cuanto a plazo y modalidades, el Estado tendrá esencialmente, aunque no exclusivamente, una obligación de hacer, es decir, de adoptar providencias y brindar los medios y elementos necesarios para responder a las exigencias de efectividad de los derechos involucrados, siempre en la medida de los recursos económicos y financieros de que disponga para el cumplimiento del respectivo compromiso internacional adquirido. Así la implementación progresiva de dichas medidas podrá ser objeto de rendición de cuentas y, de ser el caso, el cumplimiento del respectivo compromiso adquirido por el Estado podrá ser exigido ante las instancias llamadas a resolver eventuales violaciones a los derechos humanos"

"Como correlato de lo anterior, se desprende un deber -si bien condicionado- de no regresividad, que no siempre deberá ser entendido como una prohibición de medidas que restrinjan el ejercicio de un derecho. Al respecto, el Comité de Derechos Económicos, Sociales y Culturales de las Naciones Unidas ha señalado que 'las medidas de carácter deliberadamente re [gresivo] en este aspecto requerirán de la consideración más cuidadosa y deberán justificarse plenamente por referencia a la totalidad de los derechos previstos en el Pacto (Internacional de Derechos Económicos, Sociales y Culturales) y en el contexto del aprovechamiento pleno del máximo de los recursos de que [el Estado] disponga' . En la misma línea, la Comisión Interamericana ha considerado que para evaluar si una medida regresiva es compatible con la Convención Americana, se deberá 'determinar si se encuentra justificada en razones de suficiente peso'. Por todo lo expuesto, cabe afirmar que la regresividad resulta justiciable cuando de derechos económicos, sociales y culturales se trate [...]"26.

La Corte Suprema de Justicia de la Nación ha resuelto varios casos a la luz de la prohibición de regresividad.

En la causa "Milone" el Supremo Tribunal Federal, confirmó la sentencia que, luego de declarar la inconstitucionalidad del art. 14.2.b de la ley 24.557 de riesgos del trabajo (LRT), norma que disponía el pago de la indemnización por incapacidad derivada de un accidente de trabajo mediante renta periódica, había ordenado que la misma fuese satisfecha mediante un pago único. En lo pertinente la Corte señaló:

“[...] Por su parte, el art. 75, inc. 23 de la Constitución Nacional, al establecer como atribuciones del Congreso de la Nación las de legislar y promover medidas de acción positiva que garanticen la igualdad real de oportunidades y de trato, y el pleno goce y ejercicio de los

\footnotetext{
26 Corte Interamericana de Derechos Humanos, Caso Acevedo Buendía y otros ("Cesantes y Jubilados de la Contraloría) vs. Perú, op.cit. (n. 141), párrs. 102 y 103. En la nota 89 del párr. 103 se lee en lo pertinente lo siguiente: "De acuerdo con el Comité de Derechos Económicos, Sociales y Culturales, "en caso de que un Estado parte aduzca 'limitaciones de recursos' para explicar cualquier medida regresiva que haya adoptado, [...] examinará esa información en función de las circunstancias concretas del país de que se trate y con arreglo a los siguientes criterios objetivos: a)el nivel de desarrollo del país; b)la gravedad de la presunta infracción, teniendo particularmente en cuenta si la situación afecta al disfrute de los derechos básicos enunciados en el Pacto; c) la situación económica del país en ese momento, teniendo particularmente en cuenta si el país atraviesa un período de recesión económica; d)la existencia de otras necesidades importantes que el Estado Parte deba satisfacer con los recursos limitados de que dispone; por ejemplo, debido a un reciente desastre natural o a un reciente conflicto armado interno o internacional; e)si el Estado Parte trató de encontrar opciones de bajo costo [.] y f)si el Estado Parte recabó cooperación y asistencia de la comunidad internacional o rechazó sin motivos suficientes los recursos ofrecidos por la comunidad internacional para la aplicación de lo dispuesto en el Pacto". Naciones Unidas, Comité de Derechos Económicos, Sociales y Culturales, Declaración sobre la "Evaluación de la obligación de adoptar medidas hasta el 'máximo de los recursos de que disponga' de conformidad con un protocolo facultativo del Pacto", E/C.12/2007/1, 38 Período de Sesiones, 21 de septiembre de 2007, párr. 10.
} 
derechos reconocidos por la Constitución y por los tratados internacionales vigentes sobre derechos humanos, pone énfasis en determinados grupos tradicionalmente postergados, dentro de los cuales se menciona en forma expresa a las personas con discapacidad. Por tal razón una interpretación conforme con el texto constitucional indica que la efectiva protección al trabajo dispuesta en el art. 14 bis se encuentra alcanzada y complementada, en las circunstancias sub examine, por el mandato del art. 75, inc. 23, norma que, paralelamente, asienta el principio de no regresión en materia de derechos fundamentales. Así lo preceptúa también el principio de progresividad asentado en el art. 2.1 del citado Pacto Internacional de Derechos Económicos, Sociales y Culturales, en concordancia con su art. 11, inc. 1, por el que los estados han reconocido el derecho de toda persona 'a una mejora continua de las condiciones de existencia' [...]"27.

En el caso "Medina" la Corte declaró la inconstitucionalidad del art. 18 de la ley 24.557 de riesgos del trabajo (LRT) que excluía a los padres como derechohabientes de la indemnización por accidente de trabajo en caso de muerte del trabajador soltero sin otros derechohabientes. Los argumentos pertinentes del más alto Tribunal de Argentina fueron los siguientes:

“ [...]En el contexto que precede se advierte también una retrogradación de derechos consagrados por normas fundamentales - previamente receptados en las leyes que regulaban su ejercicio [...], y que fueron abrogados [...] sin razones que lo legitimen, lo cual resulta inconcebible en el diseño constitucional moderno que consagra el principio de la progresividad de los derechos sociales, que tiene por función evitar el retroceso de aquello que es conducente al logro de la justicia social (art. 75, incisos 19, 22 y 23 de la C.N.; 26 de la Convención Americana sobre los Derechos Humanos y 2 del Pacto Internacional de Derechos Económicos, Sociales y Culturales). Esta retrogradación fue señalada por la propia Corte al evaluar la LRT, afirmando que la reforma introducida por la norma que regula los infortunios laborales pone a ésta en un grave conflicto con un principio arquitectónico del derecho internacional de los derechos humanos en general, y del PIDESC en particular; agregando -con cita, incluso, del artículo 2.1 del Pacto y del Comité respectivo- que todo Estado Parte se compromete a adoptar medidas para alcanzar progresivamente la plena efectividad de los derechos reconocidos en el Tratado, puntualizando que aquéllas de carácter deliberadamente retroactivo requerirán la consideración más cuidadosa y deberán justificarse plenamente con referencia a la totalidad de los derechos previstos en el Acuerdo y en el contexto del aprovechamiento pleno del máximo de los recursos de que se disponga, derivándose una fuerte presunción contraria a que las medidas regresivas sean compatibles con el Pacto, sobre todo cuando su orientación no es otra -art. 11.1- que la mejora continua de las condiciones de existencia (v. Fallos: 327:3753, cons. 10, voto de los jueces Petracchi y Zaffaroni; y 328:1602)."

"Cabe recordar [...], que el artículo 75, inciso 23, de la Constitución Nacional fortalece la vigencia del principio de progresividad en materia previsional, descalificando todo accionar gubernamental que en la práctica dé un resultado regresivo en el goce efectivo de los derechos (v. Fallos 328:1602, voto del ministro Maqueda) [...]"28.

27 C.S.J.N., "Milone c/Asociart S.A.", op.cit. (n. 10).

28 C.S.J.N., Fallos: 331:250, 26/02/2008, "Medina, Orlando Rubén y otro c/Solar Servicios On Line Argentina S.A. y otro". Este criterio fue reiterado en Fallos: L. 257. XL, 03/06/2008, "Lescano, Demetrio y otro c/Estructuras Metalúrgicas Din S.A. y otro" y 
En el caso "Torrillo" el más Alto Tribunal admitió la posibilidad de imputar la responsabilidad prevista en el Código Civil a una aseguradora de riesgos del trabajo, por los daños a la persona de un trabajador derivados de un accidente o enfermedad laboral, en el caso que se demuestren los presupuestos de aquélla, con fundamento -entre otros- en el principio de progresividad, según lo establecido en los arts. 2.1 y 11.1 del PIDESC y en la doctrina establecida por el CDESC en la Observación general Nro. $14^{29}$.

En el caso "Pérez" la Corte declaró la inconstitucionalidad del art. 103 bis, inc. c) de la Ley de Contrato de Trabajo (texto según ley 24.700) que introdujo los llamados "beneficios sociales" con carácter no remunerativo y específicamente los "ticket canasta". En lo pertinente señaló:

“[...] el concepto que emerge del citado artículo [1] del Convenio 95 de la OIT, del año 1949, ratificado por la Argentina, mediante el decreto-ley 11.594/56, fue recogido por el legislador nacional en oportunidad de sancionar en 1974 la Ley de Contrato de Trabajo, que en su art. 103 entiende por remuneración a 'la contraprestación que debe percibir el trabajador como consecuencia del contrato de trabajo' (ley No 20.744). Allí se advierte la coincidencia del texto internacional con el local."

"Sin embargo, en el año 1996 se reformó la redacción original, y mediante la ley 24.700 se introdujo el art. 103 bis de la Ley de Contrato de Trabajo, que incorpora los llamados 'beneficios sociales' con carácter no remunerativo y específicamente los 'ticket canasta' (inciso 'c'). De este modo se alteró el esquema salarial con grave afectación del principio de progresividad de los derechos sociales, que tiene por función evitar el retroceso de aquello que es conducente al logro de la justicia social (art. 75, incisos 19, 22 y 23 de la C.N.; 26 de la Convención Americana sobre los Derechos Humanos y 2 del Pacto Internacional de Derechos Económicos, Sociales y Culturales); máxime cuando la orientación que debe guiar la efectividad de los derechos de este último pacto no debe ser otra que la mejora continua de las condiciones de existencia (art. 1 del Pacto Internacional de Derechos Económicos, Sociales y Culturales, v. Fallos: 327:3753, cons. 10, voto de los jueces Petracchi y Zaffaroni; y Fallos: 328:1602) [...]" $]^{30}$.

En el caso "Arcuri Rojas", la Corte Suprema de Justicia acogió el reclamo de una jubilación por invalidez, invocando en lo pertinente lo siguiente:

“[...] Que la posibilidad de aplicar la nueva legislación a casos regidos por regímenes anteriores ha sido admitida por esta Corte en Fallos: 308:116 y 883; 310:995; 312:2250 y 316:2054, precedentes en los que se extendió la aplicación de una norma posterior a los casos en que la muerte del causante se había producido con anterioridad a su vigencia [...]" "[...] Que sobre la base de la finalidad protectora de las disposiciones que regulan la seguridad social, esos fallos aplicaron la norma más favorable, exégesis que concuerda con el propósito del legislador de promover la progresividad de los derechos sociales, según ha sido preceptuado, más tarde, en el art. 75 inciso 23 de la Constitución Nacional y en diversos

en B. 1013. XLIII, 25/08/2009, "Barberis, Nilda María y otro c/Adecco Argentina S.A. y otro".

29 C.S.J.N., “Torrillo c/Gulf”, op.cit. (n. 26).

30 C.S.J.N., "Pérez c/Disco", op.cit. (n. 26). 
tratados de derechos humanos con jerarquía constitucional en las disposiciones del inciso 22 del artículo mencionado [...]"

“[...] Que es el reconocimiento del principio de progresividad en la satisfacción plena de esos derechos el que ha desterrado definitivamente interpretaciones que conduzcan a resultados regresivos en la materia (arts. 26 y 29 de la Convención Americana sobre Derechos Humanos y considerando $10^{\circ}$ del voto del Dr. Maqueda en Fallos: 328:1602) [...]"

“[...] Que sería estéril el esfuerzo realizado por el legislador para cumplir con la obligación establecida en el art. $1^{\circ}$ del Protocolo Adicional a la Convención Americana sobre Derechos Humanos ("Protocolo de San Salvador"), en cuanto exige que los Estados parte adopten todas las medidas necesarias hasta el máximo de los recursos disponibles para lograr progresivamente la plena efectividad de los derechos sociales, si por vía interpretativa se sustrajera de esa evolución a quienes en situación de total desamparo por aplicación de leyes anteriores que establecían un menor grado de protección, máxime cuando se encuentra demostrado que el causante y, por ende, su viuda, reúnen los requisitos necesarios para el reconocimiento de los derechos pretendidos, según han sido previstos en el actual esquema normativo $[\ldots]^{31}$.

En un reciente pronunciamiento, donde acogió un reclamo incoado contra un decreto municipal que disponía la rebaja de las remuneraciones de los empleados públicos, la Corte Suprema ratificó y profundizó su doctrina respecto al principio de progresividad en los siguientes términos:

"[...] el principio de progresividad, el cual, para lo que interesa, impone que todas las medidas estatales de carácter deliberadamente 'regresivo' en materia de derechos humanos, tal como lo es el decreto 5/2003 impugnado, requieran la consideración 'más cuidadosa', y deban 'justificarse plenamente, v.gr., con referencia a la totalidad de los derechos previstos en el PIDESC y en el contexto del aprovechamiento pleno del "máximo de los recursos" de que el Estado disponga (Observación general No 18, cit. párr. 21; asimismo, del citado Comité: Observación general No 17 -párr. 27-y 19 -párr. 42- entre otras). En este sentido se alinean conocidos antecedentes de esta Corte ('Aquino', cit., ps. 3774/3776; 'Madorrán', cit., p. 2004; 'Milone', Fallos: 327:4697, 4619 -2004-; 'Torrillo', cit., p. 722; asimismo: 'Medina, Orlando Rubén y otros c/ Solar Servicios On Line Argentina S.A, Fallos: 321:250 y sus citas -2008-; 'Silva, Facundo Jesús c/Unilever Argentina S.A.' Fallos 330:5435, 5454 -2007- voto de los jueces Fayt y Petracchi; 'Sánchez, María del Carmen c/ANSes', Fallos: 328:1602, 1624/1625 -2005- voto del juez Maqueda). En términos idénticos, es dable agregar y destacar en esta oportunidad, debe entenderse el art. 26 de la Convención Americana sobre Derechos Humanos, atinente al desarrollo progresivo de los derechos económicos, sociales y culturales, según lo expresa la señera y cercana sentencia de la Corte IDH dictada en el Caso Acevedo Buendía y otros ('Cesantes y Jubilados de la Contraloría') vs. Perú (excepción preliminar y fondo, 1-1-2009, Serie C No 198, párrs. 102/103); asimismo: Comisión Interamericana de Derechos Humanos, informe $\mathrm{n}^{\circ}$ 27/09, caso 12.249, Jorge Odir Miranda Cortez y otros - El Salvador, 20-3-2009, párr. 105 y ss.). Es de recordar, para este orden regional y el citado art. 26, que los Estados miembros

31 C.S.J.N., Fallos: 332:2454, 03/11/2009, “Arcuri Rojas, Elsa”. 
de la OEA, convencidos de que el hombre sólo puede alcanzar la plena realización de sus aspiraciones dentro de un 'orden social justo', convinieron en dedicar sus 'máximos esfuerzos' a la aplicación, entre otros, del principio según el cual 'el trabajo debe prestarse en condiciones que, incluyendo un régimen de salarios justos, aseguren la vida, la salud y un nivel económico decoroso para el trabajador y su familia' (art. 45.b)."

"En todo caso, ha de tenerse muy presente que existe una "fuerte presunción" contraria a que dichas medidas regresivas sean compatibles con el PIDESC, según lo proclama el mencionado Comité de Derechos Económicos, Sociales y Culturales en la recordada Observación general No 18 (párr. 34), continuadora de doctrina ya enunciada en documentos análogos en otras materias (v.gr. Observación general No 14 -párr. 32-, 15 -párr. 19-, 17 -párr. 27), así como también lo ha hecho esta Corte ('Medina', cit., p. 259 y sus citas; v. asimismo: 'Aquino', cit., p. 3775, y 'Silva', cit., p. 5454). La regresividad, en suma, 'contraría los postulados y el espíritu del corpus juris de los derechos humanos' (Caso Acevedo Buendía..., cit., voto del juez García Ramírez, párr. 21) [...]”32.

Se impone, por último, reiterar que en el trascendental fallo precitado, el Supremo Tribunal Federal agregó, en apoyo de su decisión que las llamadas "medidas de ajuste" derivadas de "crisis económicas" y una "grave escasez de recursos", hacen que los esfuerzos de las autoridades por proteger los derechos económicos, sociales y culturales adquieran una urgencia "mayor, no menor", y que la "protección" de las "capas vulnerables de la población" es, precisamente, "el objetivo básico del ajuste económico". Señaló, además, la Corte Suprema que todo equilibrio entre las reformas económicas y la protección de los derechos humanos, obliga a proteger "en particular a los grupos más vulnerables", cuanto más en el campo laboral y salarial, en el cual, todos los poderes públicos, dentro de la órbita de sus respectivas competencias, "deben hacer prevalecer el espíritu protector que anima" al art. 14 bis de la Constitución Nacional, tutela ésta que, por ende, impone un particular enfoque para el control de constitucionalidad ${ }^{33}$.

\section{XVII}

La razón de ser de los derechos fundamentales es fijar ciertos límites al poder, de modo que el individuo tenga la posibilidad de reaccionar frente a los abusos que incidan en su esfera de libertad. Lo que ocurre es que en la tradición liberal sólo se contemplaba como hipótesis relevante la posible injerencia del Estado, dado que la Constitución le atribuía competencias cuyo ejercicio entraba en colisión tendencialmente, por su propia lógica, con esa esfera de autonomía individual. Pero, una vez que se toma conciencia del peligro potencial que entrañan las posiciones de prepotencia de algunos sujetos formalmente privados, no parece que haya razones de peso para discriminar entre atentados imputables a los poderes públicos y atentados cometidos por particulares ${ }^{34}$.

El poder privado aflora como tal en aquellas situaciones caracterizadas por "una disparidad sustancial entre las partes". Esta falta de "simetría" permite que la parte que por razones econó-

\footnotetext{
$32 \quad$ C.S.J.N., "Asociación de Trabajadores del Estado", op.cit. (n. 26).

33 Ibid.

34 Bilbao, Juan María. La eficacia de los derechos fundamentales frente a particulares. Análisis de la jurisprudencia del Tribunal Constitucional. España, Madrid: Boletín Oficial del Estado. Centro de Estudios Políticos y Constitucionales, 1997, p. 326.
} 
micas o sociales se encuentra en "posición dominante" condicione la decisión de la parte "débil". Lo que se ejerce en estos casos es un poder que es privado en lo que concierne a su fuente y a los sujetos implicados, pero cuyo acto de ejercicio se realiza, sin embargo, con formas de coacción y autoridad asimilables sustancialmente a las categorías propias de poderes de derecho público. Cuando esta posición dominante se institucionaliza estamos en presencia de un verdadero poder de "supremacía privada", que asume una "relevancia social" y, en última instancia, pública, relegando a la contraparte a una posición de virtual "sujeción", cuando no de "indefensión" 35 .

No cabe sorprenderse de que la génesis y el desarrollo más fecundo de la teoría de la "Drittwirkung" de los derechos fundamentales haya tenido como escenario el campo de las relaciones laborales. Esta doctrina nace precisamente en los tribunales laborales y sigue encontrando entre los cultivadores de esta disciplina los más firmes apoyos.

La empresa, como organización económica, estructurada jerárquicamente, genera una situación de poder y, correlativamente, otra de subordinación del trabajador, en cuyo marco los poderes del empresario constituyen una amenaza potencial para los derechos fundamentales del trabajador, dada la fuerte implicación de la persona de éste en la ejecución de la prestación laboral ${ }^{36}$.

En Europa, el detonante que hizo estallar la polémica, colocando la cuestión en primer plano, fue la formulación por H. C. Nipperdey de la doctrina de la "Drittwirkung der Grundrechte" ("la eficacia frente a terceros de los derechos fundamentales"), una tesis que encontró eco en la jurisprudencia del Bundesarbeitsgericht (el Tribunal Federal de Trabajo alemán) y, más concretamente, de la Sala Primera que él mismo presidía.

Nipperdey, prestigioso especialista en Derecho Civil y Laboral, es consciente de que en la sociedad de masas determinados grupos disponen de importantes parcelas de poder social y económico, un poder que es capaz de afectar intensamente un gran número de individuos en aspectos relevantes de su vida. A su juicio en la Ley Fundamental se enuncian una serie de derechos, como la libertad de circulación, la libertad de reunión, la inviolabilidad del domicilio, o el derecho de asilo, que sólo vinculan a los poderes públicos. Pero existen también preceptos que reconocen derechos fundamentales que garantizan a cada ciudadano un "status socialis", una esfera de libertad constitucionalmente protegida frente a los prepotentes "Sozialmachte". Y menciona, entre otros, la dignidad humana, el libre desarrollo de la personalidad, la libertad de expresión, el principio de igualdad salarial entre hombres y mujeres, la prohibición de discriminación, la libertad de conciencia, la libertad de asociación y el secreto de las comunicaciones. Cuando Nipperdey preconiza a principios de los 50 dẹl siglo 20 la eficacia inmediata de los derechos fundamentales, lo que propone es una solución provisional (la aplicación directa por los jueces), ante la evidencia de que el Bundestag (el primero se eligió en 1949) no estaba dispuesto a desarrollar legislativamente en todos los campos el programa recogido en la Constitución. A tal efecto, el jurista alemán adoptó un concepto de Constitución como un orden de valores del que se pueden extraer directamente reglas para resolver jurídicamente casos concretos ${ }^{37}$.

La primera sentencia en que se sugiere esa relevancia directa en las relaciones inter privatos es de 3 de diciembre de 1954. En ella se recoge la afirmación de que los derechos fundamentales contienen "principios ordenadores para la vida social", de carácter vinculante, que tienen una "significación inmediata" ("unmittelbare Bedeutung") para el tráfico jurídico privado, por lo que

\footnotetext{
Ibid y la citada en su nota 27, p. 245.

36 Ibid, pp. 246-247.

$37 \quad$ Ibid, p. 271.
} 
ningún negocio o acto jurídico privado puede estar en contradicción con lo que se podía llamar la estructura de un determinado ordenamiento, con sus principios básicos ${ }^{38}$.

Defender la tesis de la eficacia inmediata frente a terceros es afirmar la virtualidad directa, sin mediaciones que concreticen los derechos fundamentales, en tanto que derechos subjetivos reforzados por la garantía constitucional, frente a las violaciones procedentes de sujetos privados.

Si se toma en serio el carácter normativo de la Constitución (la "Drittwirkung" sería algo así como la última frontera de la Constitución normativa) no se puede negar, a limine y categóricamente, cualquier atisbo de eficacia directa en tal sentido.

Como señalamos precedentemente (ver capítulo V), ya la Corte Suprema había destacado enfáticamente casi cuatro décadas antes de la reforma constitucional de 1994, que nada hay, ni en la letra ni en el espíritu de la Constitución, que permita afirmar que la protección de los llamados "derechos humanos" - porque son los derechos esenciales del hombre- esté circunscripta a los ataques que provengan sólo de la autoridad ${ }^{39}$.

El Supremo Tribunal Federal afirmaba al resolver el citado caso:

“[...] Además de los individuos humanos y el Estado, hay ahora una tercera categoría de sujetos, con o sin personalidad jurídica, que sólo raramente conocieron los siglos anteriores: los consorcios, los sindicatos, las asociaciones profesionales; las grandes empresas, que acumulan casi siempre un enorme poderío material o económico. A menudo sus fuerzas se oponen a las del Estado y no es discutible que estos entes colectivos representan, junto con el progreso material de la sociedad, una fuente de amenazas para el individuo y sus derechos esenciales".

"Si en presencia de estas condiciones de la sociedad contemporánea, los jueces tuvieran que declarar que no hay protección constitucional de los derechos humanos frente a tales organizaciones colectivas, nadie puede engañarse que tal declaración comportaría la de la quiebra de los grandes objetivos de la Constitución y, con ella, la del orden jurídico fundamental del país..."

La doctrina de la eficacia inmediata implica que, con normativa legal de desarrollo o sin ella, es la norma constitucional la que se aplica como "razón primaria y justificadora" (no necesariamente la única) de una determinada decisión. Es decir, no como "regla hermenéutica, sino como norma de comportamiento apta para incidir también en el contenido de las relaciones entre particulares".

La existencia de una norma legal que reitera expresamente la regla o el principio enunciado en la Constitución no es óbice para que pueda hablarse de aplicación directa de la norma constitucional y de eficacia inmediata del derecho fundamental. La función del legislador es, en estos casos, declarativa, no constitutiva ${ }^{41}$.

El reconocimiento de la eficacia inmediata entre particulares es una especie de cláusula de cierre del sistema de protección de los derechos fundamentales. Esta tutela derivada directamente del texto constitucional colmaría las lagunas de la regulación legal, cubriendo supuestos no contemplados específicamente, y supliría también las limitaciones de los instrumentos de control

$38 \quad$ Ibid, p. 272 y nota 87.

39 C.S.J.N., "Samuel Kot S.R.L., op.cit. (n. 24).

40 Ibid.

a1 BilbaO, Juan María. op. cit. (n. 163), p. 327. 
propios del Derecho privado. La experiencia indica que los dispositivos genuinamente privados ofrecen protección "genérica" y "fragmentaria", por lo que se hace necesario en no pocos casos acudir directamente a las garantías constitucionales ${ }^{42}$.

El mandato primero que los jueces argentinos reciben de la Constitución que juran cumplir es el de asegurar el goce y pleno ejercicio de las garantías superiores para la efectiva vigencia del Estado de Derecho ${ }^{43}$.

Donde hay un derecho hay un remedio legal para hacerlo valer toda vez que sea desconocido; principio del que ha nacido la acción de amparo, pues las garantías constitucionales existen y protegen a los individuos por el solo hecho de estar en la Constitución e independientemente de sus leyes reglamentarias, cuyas limitaciones no pueden constituir obstáculo para la vigencia efectiva de dichas garantías ${ }^{44}$.

La ausencia de norma legal que contemple los derechos fundamentales no es óbice para que los jueces arbitren las medidas apropiadas y oportunas para una tutela efectiva de los derechos constitucionales que se aducen vulnerados. Basta la comprobación inmediata de un gravamen para que una garantía constitucional deba ser restablecida por los jueces en su integridad, sin que pueda alegarse en contrario la inexistencia de una ley que la reglamente: las garantías individuales existen y protegen a los individuos por el solo hecho de estar consagradas por la Constitución e independientemente de las leyes reglamentarias. En apoyo de tal afirmación, la Corte Suprema de Justicia de la Nación sostuvo que ya a fines del siglo XIX señalaba Joaquín V. González:

"No son, como pude creerse, las 'declaraciones, derechos y garantías', simples fórmulas teóricas: cada uno de los artículos y cláusulas que las contienen poseen fuerza obligatoria para los individuos, para las autoridades y para toda la Nación. Los jueces deben aplicarla en la plenitud de su sentido, sin alterar o debilitar con vagas interpretaciones o ambigüedades la expresa significación de su texto. Porque son la defensa personal, el patrimonio inalterable que hace de cada hombre, ciudadano o no, un ser libre e independiente dentro de la Nación Argentina" ("Manual de la Constitución Argentina", en "Obras completas", vol. 3, Buenos Aires, 1935, núm. 82; confr., además, núms. 89 y 90$)^{45}$.

Los derechos constitucionales tienen un contenido que, por cierto, lo proporciona la propia Constitución. De lo contrario, debería admitirse una conclusión insostenible: que la Constitución Nacional enuncia derechos huecos, a ser llenados de cualquier modo por el legislador, o que no resulta más que un promisorio conjunto de sabios consejos, cuyo seguimiento quedaría librado a la buena voluntad de este último.

Todo ello explica que la determinación de dicho contenido configure, precisamente, uno de los objetos de estudio centrales del intérprete constitucional. Explica también que al reglamentar un derecho constitucional, el llamado a hacerlo no pueda obrar con otra finalidad que no sea la de dar a aquél toda la plenitud que le reconozca la Constitución Nacional. Los derechos constitucionales son susceptibles de reglamentación, pero esta última está destinada a no alterarlos (art. 28, $\mathrm{CN}$ ), lo cual significa conferirles la extensión y comprensión previstas en el texto que los enunció y

\footnotetext{
$42 \quad$ Ibid, p. 328.

43 C.S.J.N., Fallos: 329:5266, 21/11/2006, "Asociación Lucha por la Identidad Travesti - Transexual c/Inspección General de Justicia"

44 C.S.J.N., "Ekmekdjian c/Sofovich y otros", op.cit. (n. 7), entre otras.

45 C.S.J.N., Fallos: 332:111, 24/02/2009, “Halabi, Ernesto c/P.E.N. -ley 25.873- dto. 1563/04".
} 
que manda a asegurarlos. Es asunto de legislar, sí, pero para garantizar "el pleno goce y ejercicio de los derechos reconocidos por esta Constitución y por los tratados internacionales vigentes sobre derechos humanos" (Constitución Nacional, art. 75 inc. 23).

El mandato que expresa el art. 14 bis de la Constitución Nacional se dirige primordialmente al legislador, pero su cumplimiento atañe asimismo a los restantes poderes públicos, los cuales, dentro de la órbita de sus respectivas competencias, deben hacer prevalecer el espíritu protector que anima a dicho precepto ${ }^{46}$.

En materia de derechos humanos laborales, la Corte Interamericana de Derechos Humanos ha señalado expresamente que por la teoría del Drittwirkung, según la cual los derechos fundamentales deben ser respetados tanto por los poderes públicos como por los particulares en relación con otros particulares, en el marco de la relación laboral privada el empleador debe respetar los derechos humanos de sus trabajadores ${ }^{47}$.

En materia de derechos humanos, rige una presunción de autoejecución o autoaplicabilidad (self-executing) de las normas sustantivas contenidas en los tratados respectivos, excepto si contienen una estipulación expresa de su ejecución por medio de leyes subsecuentes, que condicionen enteramente el cumplimiento de las obligaciones contraídas.

En el mismo sentido, Barbagelata afirma que no es razonable atribuir a los redactores de un instrumento internacional sobre derechos humanos el propósito de introducir disposiciones desprovistas de efectividad, por lo que hay que convenir que la autoejecución y la autoaplicabilidad deben presumirse. Esa presunción sólo cedería ante la imposibilidad absoluta de darle esos efectos a las disposiciones en cuestión, sea porque no se logra, por el momento, atribuirles un contenido concreto, o porque se remiten a reglamentaciones o implementaciones que deben ser producidas por el derecho interno ${ }^{48}$.

El art. 28 de la Declaración Universal de Derechos Humanos dispone: "Toda persona tiene derecho a que se establezca un orden social internacional en el que los derechos y libertades proclamados en esta Declaración se hagan plenamente efectivos".

El contenido y alcance de la apertura constitucional al Derecho Internacional de los Derechos Humanos Laborales y de la relación complementaria entre ambos órdenes jurídicos, dependen no sólo del entramado técnico jurídico que las sustenta, sino de la voluntad de los operadores jurídicos, incluidos los jueces, de su conciencia jurídica respecto a la necesidad o no de hacer plenamente efectivos esos derechos, de los condicionamientos económicos, sociales y culturales, y de las concretas relaciones de poder en el seno de la sociedad, tanto a escala nacional, como regional y mundial.

Por otra parte, como señala Ramos Filho, comprendiendo el carácter ambivalente del Derecho Capitalista del Trabajo -que, atribuyendo derechos a la clase trabajadora, "legaliza" la explotación y la subordinación de los trabajadores, no solamente al poder del empleador, sino también a la forma de vida propuesta por el modo de producción y "orienta" la distribución social de la riqueza-, la clase trabajadora, en varios países, actualmente retoma importantes procesos de lucha y de movilización con la finalidad de materializar conquistas concretas en la regulación estatal de las relaciones de trabajo y en las condiciones de vida de los pueblos ${ }^{49}$.

Esa tensión de intereses contrapuestos y su desenlace en cada momento histórico contribuyen también a explicar el contenido y el alcance del Derecho Universal de los Derechos Humanos Laborales y su efectiva aplicación en el orden nacional, regional y universal.

\footnotetext{
46 C.S.J.N., "Vizzoti c/Amsa S.A.", op.cit. (n. 26).

47 Corte Interamericana de Derechos Humanos. Opinión consultiva, op.cit. (n. 94).

48 Barbagelata, Héctor Hugo, op.cit. (n. 2), p. 248.

49 Ramos, Wilson. Direito Capitalista do Trabalho. História, Mitos e Perspectivas no Brasil. Sao Paulo, Brasil: LTr, 2012 , p. 465.
} 